\begin{tabular}{|c|c|c|c|}
\hline \multirow{2}{*}{$\begin{array}{r}\text { Case Reports in } \\
\text { Gastroenterology }\end{array}$} & \multicolumn{2}{|c|}{ Case Rep Gastroenterol 2016;10:506-511 } & \multirow[b]{2}{*}{$\begin{array}{l}\text { Karger } \\
\text { Open access }\end{array}$} \\
\hline & $\begin{array}{l}\text { DOI: } 10.1159 / 000448886 \\
\text { Publisned onine:. Uctover 6, } 2016\end{array}$ & $\begin{array}{l}\text { (c) } 2016 \text { The Author(s) } \\
\text { Published by S. Karger AG, Basel } \\
\text { www.karger.com/crg }\end{array}$ & \\
\hline & $\begin{array}{l}\text { This article is licensed under th } \\
\text { International License (CC BY-NC) } \\
\text { Usage and distribution for comme }\end{array}$ & $\begin{array}{l}\text { mons Attribution-NonCommercial } \\
\text { ger.com/Services/OpenAccessLicense) } \\
\text { fuires written permission. }\end{array}$ & \\
\hline
\end{tabular}

\title{
Successful Endoscopic Submucosal Dissection of a Large Terminal Ileal Lipoma
}

\author{
Hisatsugu Noda Naotaka Ogasawara Yasuhiro Tamura \\ Yoshihiro Kondo Shinya Izawa Masahide Ebi Yasushi Funaki \\ Makoto Sasaki Kunio Kasugai \\ Department of Gastroenterology, Aichi Medical University School of Medicine, \\ Nagakute, Japan
}

\section{Keywords}

Endoscopic submucosal dissection · Lipoma - Submucosal tumor

\begin{abstract}
A 78-year-old woman who had recurrent right lower abdominal pain for about 1 year underwent computed tomography (CT) because of a follow-up observation 1 year after right breast cancer surgery. CT revealed a tumor in the colon. The patient was referred to our hospital for detailed examinations. An abdominal CT showed a low-density tumor of approximately $30 \mathrm{~mm}$ in the ascending colon, and the $\mathrm{CT}$ density inside the tumor was same as that of fatty tissues. A subsequent colonoscopy showed a submucosal tumor (SMT) in the proximal ascending colon developing from the terminal ileum. A colonoscopic ultrasonography revealed that the SMT was a high-echoic mass mainly localized in the submucosal layer. Based on the findings from $\mathrm{CT}$, colonoscopy, and colonoscopic ultrasonography, the SMT was diagnosed as a pedunculated lipoma originating from the terminal ileum and treated with endoscopic submucosal dissection (ESD) because of recurrent abdominal pain. The 40$\mathrm{mm}$ tumor was resected en bloc without complications. ESD may be more appropriate than polypectomy and surgery for removal of small intestinal tumors, because ESD allows direct visualization of the cutting line and exactly dissects the submucosal layers without damaging the muscular layers. ESD is a potentially useful treatment to remove intestinal lipomas.
\end{abstract}


Noda et al.: Successful Endoscopic Submucosal Dissection of a Large Terminal Ileal Lipoma

\section{Introduction}

Lipomas of the gastrointestinal tract are usually asymptomatic, benign, and submucosal tumors (SMTs) [1]. Lipomas account for $4 \%$ of 4,000 cases of benign neoplasms of the gastrointestinal tract [2]. The most common site in the gastrointestinal tract is the colon (64\%), particularly the cecum, followed by the small bowel (31\%), stomach (3\%), and esophagus $(12 \%)[2,3]$. Most patients harboring lipomas in the small bowels are asymptomatic, and therefore lesions are incidentally discovered. However, patients with large-sized lipomas in the small bowels present various symptoms, such as abdominal pain, bleeding, constipation, and intestinal obstruction or intussusceptions $[4,5]$. Treatment for a gastrointestinal lipoma is often unnecessary because of the small possibility of malignant changes. However, lipoma treatment is required when a lipoma is difficult to distinguish from other malignant tumors or when patients complain of symptoms [6,7]. Most cases of symptomatic lipomas in the small bowels are treated with surgical resection [8-10], but a few cases are treated with endoscopic resection because of technological advances in endoscopic procedures and equipment $[11,12]$. Endoscopic submucosal dissection (ESD) has recently been developed for en bloc resection of gastric and colonic neoplastic tumors [13, 14]. This technique is considered to be applicable to lipoma removal in the gastrointestinal tracts.

Herein, we report a case of lipoma located in the terminal ileum that was completely removed by ESD.

\section{Case Report}

A 78-year-old woman underwent computed tomography (CT) because of a follow-up observation 1 year after right breast cancer surgery, and CT revealed a tumor in the colon. The patient was referred to our hospital for detailed examinations in November 2015. She had had recurrent right lower abdominal pain for about 1 year. She had no previous medical history other than the right breast cancer, and her family history was unremarkable. Physical examination revealed tenderness of the right lower abdomen, and the initial laboratory data were within normal limits. An abdominal CT showed a low-density tumor measuring approximately $30 \mathrm{~mm}$ in its largest dimension in the ascending colon (fig. 1a). The tumor was well circumscribed and had a smooth demarcation. The CT density inside the tumor was the same as that of fatty tissues, and the CT density of the tumor circumference was same as that of the mucosal layer of the small intestine (fig. 1a). An air contrast barium enema revealed an elevated lesion of approximately $40 \mathrm{~mm}$ in diameter with a smooth surface (fig. 1b). A colonoscopy showed an SMT in the proximal ascending colon developing from the terminal ileum (fig. 2a, b). The tumor was pedunculated, and the cushion sign associated with tumor was present (fig. 2c). A colonoscopic ultrasonography revealed that the SMT was a high-echoic mass mainly localized in the submucosal layer (fig. 2d). Based on the above findings, the SMT was diagnosed as a pedunculated lipoma originating from the terminal ileum and treated with ESD because of recurrent abdominal pain.

A physiological saline with indigo carmine dye was injected into the basal portion of the tumor (fig. 3a). This portion of the tumor was incised using an SB knife (Sumitomo Bakelite, Tokyo, Japan), and the submucosal layer of the basal portion was dissected (fig. 3b, c). The 40-mm tumor was resected en bloc, and the resected SMT showed a yellowish inner substance, which coincides with the lipoma finding. No complications occurred during or after 
Noda et al.: Successful Endoscopic Submucosal Dissection of a Large Terminal Ileal Lipoma

ESD. The patient was discharged 4 days after the surgery without complications and was relieved of symptoms afterwards.

\section{Discussion}

Small-sized lipomas are usually asymptomatic and incidentally detected during endoscopic or radiological examinations, but those $>2 \mathrm{~cm}$ in size occasionally manifest clinical symptoms including bleeding, abdominal pain, intussusceptions, and obstruction [15]. Treatment of small-sized lipomas is often unnecessary because of the small possibility of malignant changes or few symptoms. However, large-sized lipomas commonly cause clinical symptoms, and treatment is required. Moreover, large-sized lipomas may hold malignant potential or are difficult to be distinguished from other malignant tumors. Therefore, treatment for large-sized lipomas is recommended $[6,7]$.

In our case, the patient had recurrent right lower abdominal pain attributable to the lipoma of the terminal ileum, which may cause intestinal intussusception. Surgical resection, including laparoscopic surgery, is a common treatment for lipomas of the small bowel [16]. A PubMed search for the last 10 years yielded only 2 reports of patients with lipomas in the small intestine treated with endoscopic resection; one was a giant ileal lipoma treated with endoscopic unroofing submucosal dissection [11], and the other was a lipoma of the jejunum removed by endoscopic resection using an SB knife. To our knowledge, no report of ESD for ileal lipoma has been published, although Sugimoto et al. [13] reported a case with an ileal adenoma removed with ESD after total colectomy due to familial adenomatous polyposis. Removal of a 2-cm colonic lipoma treated with polypectomy harbors a greater risk of perforation compared with the removal of a $\leq 2-\mathrm{cm}$ colonic lipoma [17]. Polypectomy is considered to pose the risk of resecting the muscle layer, because of the lack of direct visualization of the inner part of the cutting line. On the other hand, ESD allows direct visualization of the inner part of the cutting line and exact dissection of the submucosal layers without damaging the muscular layers. Therefore, ESD is considered to be safer than polypectomy for intestinal lipomas [12]. Endoscopic snare polypectomy is easy and conventional for removing pedunculated-type polyps. However, in our case, the tumor was extremely large, and had to be removed using the largest snare $33 \mathrm{~mm}$ in diameter. Moreover, tumor removal by endoscopic snare polypectomy was speculated to raise the possibility of intestinal perforation. Therefore, ESD was chosen to remove the ileal lipoma in our case, and the en bloc resection of the large lipoma was successful.

In conclusion, the large ileal lipoma was safely removed with ESD without complications, and ESD may be a potentially useful treatment to remove intestinal lipomas.

\section{Acknowledgements}

We would like to thank Editage (www.editage.jp) for English language editing.

\section{Statement of Ethics}

The authors have no ethical conflicts to disclose. Informed consent was obtained from the patient. 


\section{Case Reports in \\ Gastroenterology}

Noda et al.: Successful Endoscopic Submucosal Dissection of a Large Terminal Ileal Lipoma

\section{Disclosure Statement}

K. Kasugai received research grants and lecture fees from AstraZeneca K.K., Daiichi Sankyo Co., Ltd., and Takeda Pharmaceutical Co., Ltd.

\section{References}

1 Chung YF, Ho YH, Nyam DC, Leong AF, Seow-Choen F: Management of colonic lipomas. Aust NZ J Surg 1998;68:133-135.

2 Mayo CW, Pagtalunan RJ, Brown DJ: Lipoma of the alimentary tract. Surgery 1963;53:598-603.

3 Michowitz M, Lazebnik N, Noy S, Lazebnik R: Lipoma of the colon. A report of 22 cases. Am Surg 1985;51:449-454.

4 Ladurner R, Mussack T, Hohenbleicher F, Folwaczny C, Siebeck M, Hallfeld K: Laparoscopic-assisted resection of giant sigmoid lipoma under colonoscopic guidance. Surg Endosc 2003;17:160.

5 Yu HG, Ding YM, Tan S, Luo HS, Yu JP: A safe and efficient strategy for endoscopic resection of large, gastrointestinal lipoma. Surg Endosc 2007;21:265-269.

6 Murray MA, Kwan V, Williams SJ, Bourke MJ: Detachable nylon loop assisted removal of large clinically significant colonic lipomas. Gastrointest Endosc 2005;61:756-759.

-7 El-Khalil T, Mourad FH, Uthman S: Sigmoid lipoma mimicking carcinoma: case report with review of diagnosis and management. Gastrointest Endosc 2000;51:495-496.

8 Baskaran V, Patnaik PK, Seth AK, Dogra R, Chaudhry R: Intestinal lipoma: a rare cause of lower gastrointestinal haemorrhage. Trop Gastroenterol 2003;24:208-210.

-9 Pezzoli A, Pennazio M, Fusetti N, Simone L, Zelante A, Cifalà V, Sprujevnik T, Carella A, Gullini S: Occult intestinal haemorrhage due to lipoma of the small bowel detected with the combined use of the new endoscopic techniques. A report of two cases. Dig Liver Dis 2008;40:306-309.

$>10$ Chou JW, Feng CL, Lai HC, Tsai CC, Chen SH, Hsu CH, Cheng KS, Peng CY, Chung PK: Obscure gastrointestinal bleeding caused by small bowel lipoma. Intern Med 2008;47:1601-1603.

11 Morimoto T, Fu KI, Konuma H, Izumi Y, Matsuyama S, Ogura K, Miyazaki A, Watanabe S: Peeling a giant ileal lipoma with endoscopic unroofing and submucosal dissection. World J Gastroenterol 2010;16:1676-1679.

12 Toya Y, Endo M, Orikasa S, Sugai T, Matsumoto T: Lipoma of the small intestine treated with endoscopic resection. Clin J Gastroenterol 2014;7:502-505.

13 Sugimoto T, Okamoto M, Mitsuno Y, Kondo S, Ogura K, Ohmae T, Mizuno H, Yoshida S, Isomura Y, Yamaji Y, Kawabe T, Omata M, Koike K: Endoscopic submucosal dissection is an effective and safe therapy for early gastric neoplasms: a multicenter feasible study. J Clin Gastroenterol 2012;46: 124-129.

14 Tanaka S, Terasaki M, Kanao H, Oka S, Chayama K: Current status and future perspectives of endoscopic submucosal dissection for colorectal tumors. Dig Endosc 2012;24(suppl 1):73-79.

15 Wilson JM, Melvin DB, Gray G, Thorbjarnarson B: Benign small bowel tumor. Ann Surg 1975;181: 247-250.

-16 Tsushimi T, Matsui N, Kurazumi H, Takemoto Y, Oka K, Seyama A, Morita T: Laparoscopic resection of an ileal lipoma: report of a case. Surg Today 2006;36:1007-1011.

$\checkmark 17$ Raju GS, Gomez G: Endoloop ligation of a large colonic lipoma: a novel technique. Gastrointest Endosc 2005;62:988-990. 


\section{Case Reports in Gastroenterology}

\begin{tabular}{l|l}
\hline Case Rep Gastroenterol 2016;10:506-511 \\
\hline DOI: 10.1159/000448886 & $\begin{array}{l}\text { C 2016 The Author(s). Published by S. Karger AG, Basel } \\
\text { www.karger.com/crg }\end{array}$ \\
\hline
\end{tabular}

Noda et al.: Successful Endoscopic Submucosal Dissection of a Large Terminal Ileal Lipoma
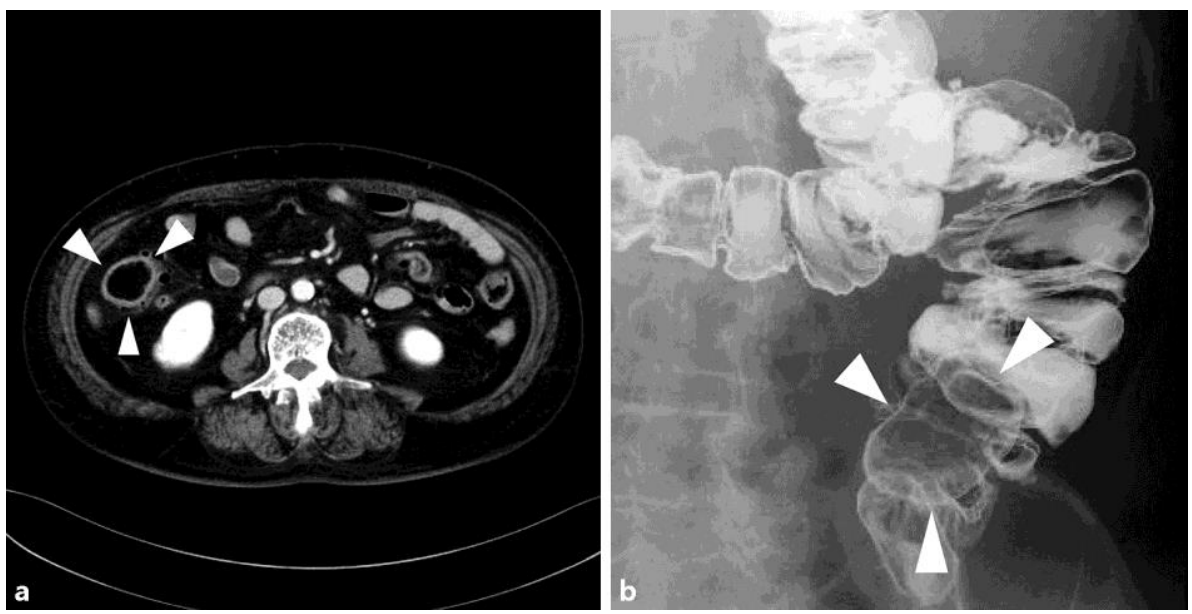

Fig. 1. a Abdominal CT showing a low-density tumor (arrowheads) in the ascending colon. b Air contrast barium enema finding. An elevated lesion with a smooth surface in the ascending colon was observed (arrowheads).
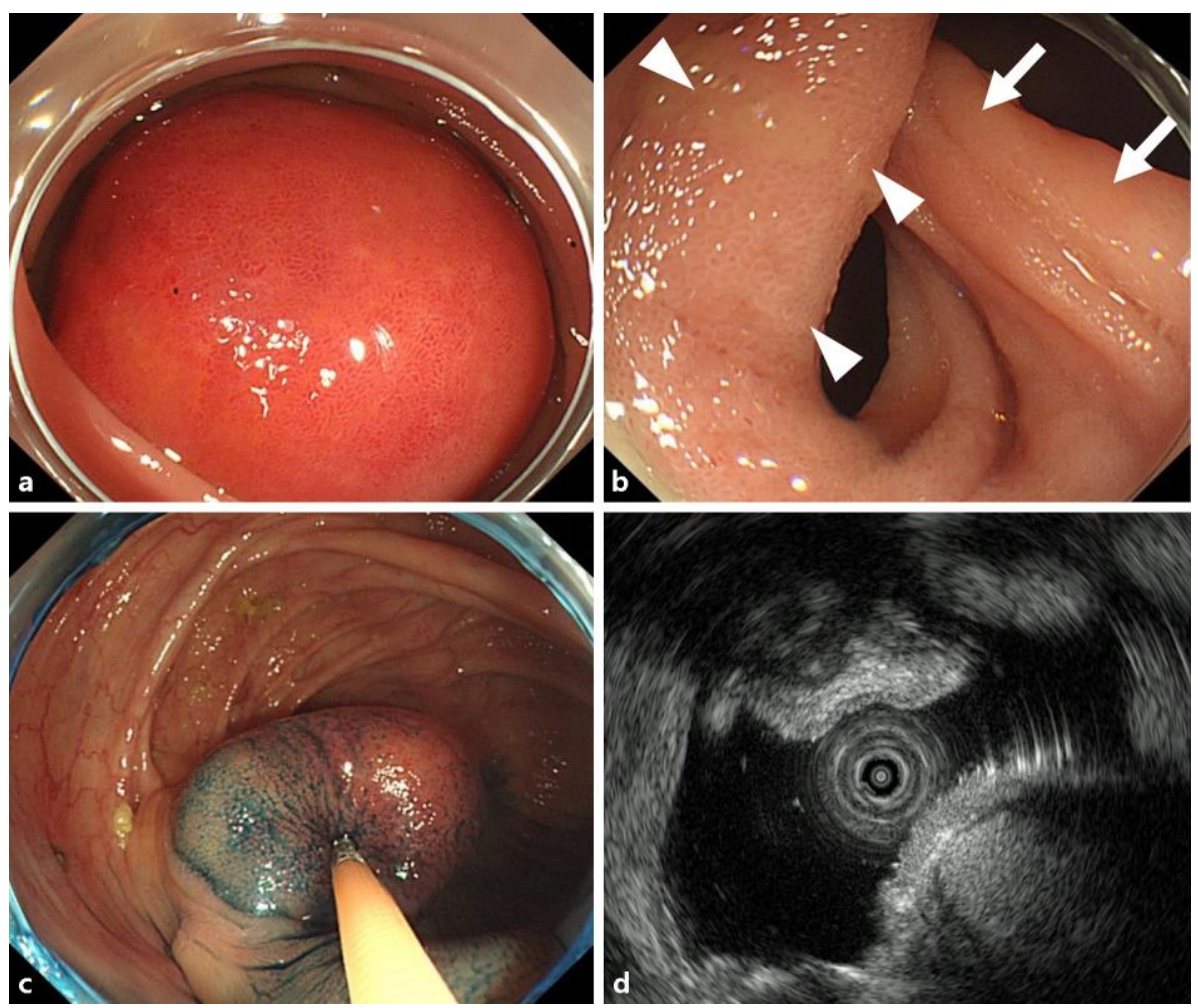

Fig. 2. a Colonoscopy showing a large SMT covered with reddish epithelial mucosa in the ascending colon. b The basal portion of the SMT consisted of small intestinal normal epithelial mucosa (arrowheads) and the Bauhin valve (arrows). The SMT was of the pedunculated type and originated from the end of the ileum. $\mathbf{c}$ The cushion sign associated with tumor was present. $\mathbf{d}$ Colonoscopic ultrasonography revealed that the SMT was a high-echoic mass mainly localized in the submucosal layer of the terminal ileum. 
Noda et al.: Successful Endoscopic Submucosal Dissection of a Large Terminal Ileal Lipoma
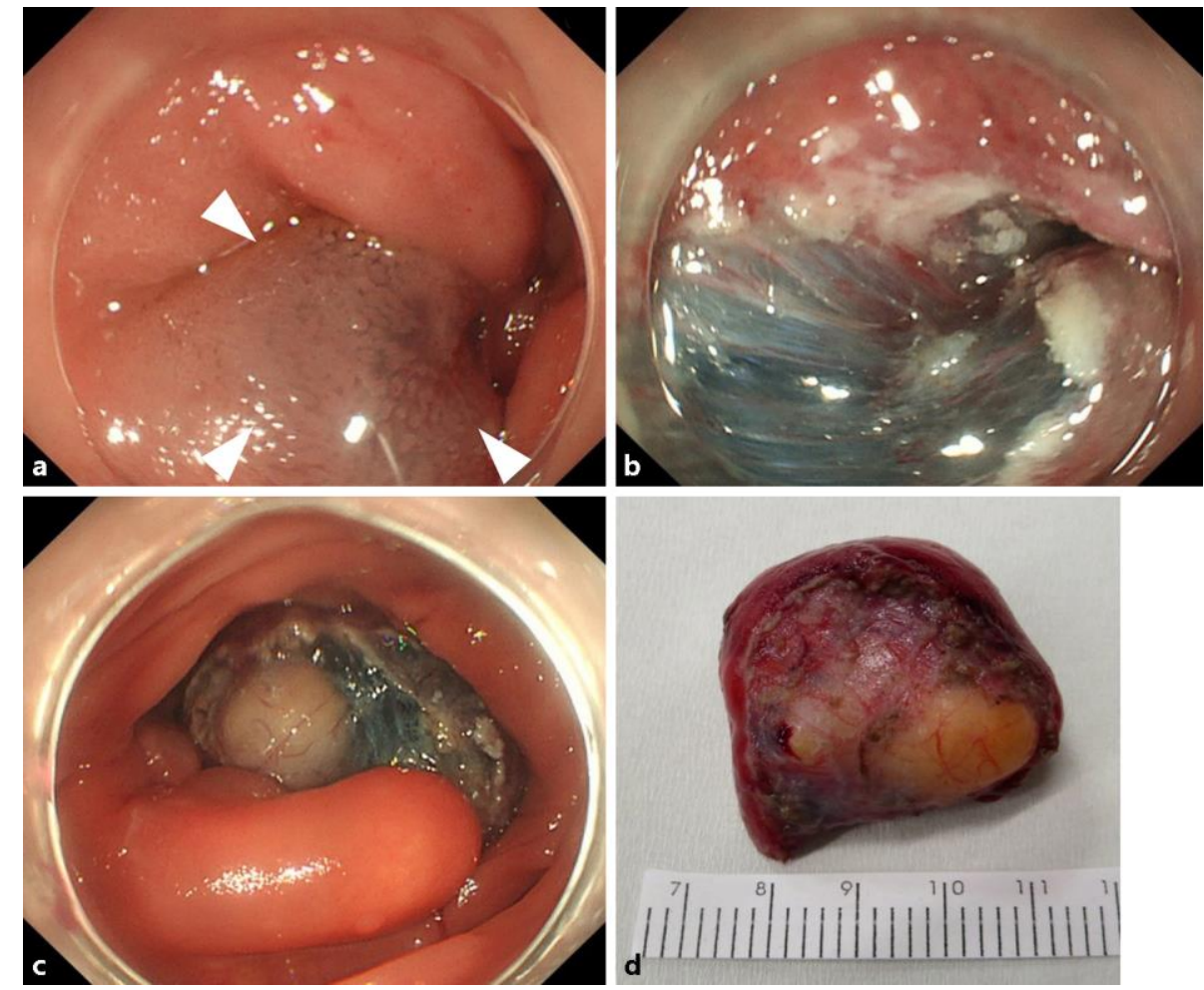

Fig. 3. a Injection of physiological saline with indigo carmine dye into the basal portion of the tumor (arrowheads). b Circumferential incision of the basal portion and submucosal dissection were performed using an SB knife. c After incising the surrounding mucosa of the basal portion from the anal side, the submucosal layer of the SMT was dissected from the anal side while observing the tumor surface. $\mathbf{d}$ Macro finding of the tumor. The inner substance of the resected 40-mm SMT was yellowish, which coincides with the lipoma finding. 